\title{
An Investigation into a Copper/Tin Alloy as an Underlying Coating to Chromium
}

\author{
Stacey Hingley and Chike Oduoza \\ University of Wolverhampton, Wulfruna Street, Wolverhampton, WV1 1LY, UK
}

Received: December 16, 2010 / Accepted: January 07, 2011 / Published: September 25, 2011.

\begin{abstract}
The electroplating industry has been under intense pressure over the last few years due to numerous factors which include the increase in metal prices, economic climate and the new regulations. These factors have led the electroplating industry to find more economical and less harmful chemicals. The characteristics and properties of a copper-tin alloy as an alternative to the nickel deposit under chromium were investigated due to the increasing concern over health risks associated with nickel metal and its soluble salts. Spectrophotometry was used to identify the colour of the deposits by using the $\mathrm{L}^{*} \mathrm{a} * \mathrm{~b} *$ colour space. The results showed that the colour of the chromium did not change regardless of the deposit below. However, there was a colour difference between the $\mathrm{Cu}-\mathrm{Sn}$ and nickel deposit, the $\mathrm{Cu}-\mathrm{Sn}$ deposit was lighter, less green and more blue than the nickel deposit with the numeric values $\mathrm{L}^{*}=86.26$, $\mathrm{a}^{*}=0.40$ and $b^{*}=3.25$, nickel proved to be the most red and most yellow in colour with the numeric values $L^{*}=83.12, a^{*}=0.81, b^{*}=6.68$. Atomic force microscopy (AFM) characterised the surface roughness of the deposits by reporting the RMS and Rmax values. The results identified the $\mathrm{Cu}-\mathrm{Sn}$ deposit to have an increased roughness to its structure with values of $8.30 \mathrm{~nm}$ and $73.0 \mathrm{~nm}$, respectively compared to the nickel deposit with values of $3.08 \mathrm{~nm}$ and $18.6 \mathrm{~nm}$ respectively. Corrosion performance was measured by two methods, (1) electrochemical test using linear polarisation and (2) accelerated corrosion test using both neutral salt spray (NSS) and copper accelerated acetic acid salt spray (CASS). The accelerated corrosion tests identified the nickel deposit to provide better corrosion protection compared to the $\mathrm{Cu}$-Sn deposit, however the electrochemical test indicated the $\mathrm{Cu}$-Sn deposit with a calculated corrosion rate of $0.232 \mathrm{~mm}$ per year would provide better corrosion protection than the nickel deposit with a corrosion rate calculated as 0.285 $\mathrm{mm}$ per year. To conclude, the $\mathrm{Cu}$-Sn deposit could not replace nickel in all applications but it could be used as an alternative to the nickel in applications where appearance was primary, but it would be unable to replace nickel where corrosion protection was foremost.
\end{abstract}

Key words: $\mathrm{Cu}-\mathrm{Sn}$ alloy, trivalent chromium, linear polarisation, AFM.

\section{Introduction}

Electrodeposited nickel is widely used in many applications. A typical application is the corrosion protection it offers in conjunction with chromium plating. The reclassification of nickel and its salts to a more toxic chemical status has led the electroplating industries to research into a replacement for the nickel layer. This paper investigates if an alloy of copper and tin could be a suitable replacement for the nickel deposit under chromium. The colour, corrosion protection and surface imaging of the $\mathrm{Cu}-\mathrm{Sn}$ deposit will be compared to the nickel deposit.

Corresponding author: Stacey Hingley, Ph.D., research field: electroplating. E-mail: s.l.handy@wlv.ac.uk.

\subsection{Background}

In 1996, an EU risk assessment was set up to investigate nickel and its compounds with regard to the effect it has on human health and also the environmental impact. EU risk assessment evaluates and sets out controls for existing substances imported into the EU when volumes exceed 10 tonnes per year. For this to happen the nickel substances in question need to be on the priority list and a Member State volunteers to act as Rapporteur. In this case, it is the Danish Environmental Protection Agency (D-EPA). There are five listed priority substances undergoing risk assessment. Since 1996 nickel metal and nickel sulphate have been on the 3rd priority list and since 2000, nickel chloride, nickel nitrate and nickel 
carbonate have been on the 4th priority list.

In February 2007, there was a reclassification of the five nickel substances. Soluble nickel compounds (nickel sulphate, chloride, nitrate and carbonate) became classified as category 1 human carcinogens by inhalation (known to be carcinogenic to man), category 2 reproductive toxicants (may cause harm to the unborn child) and chronic toxicant (T; R48-23). Nickel metal became classified as category 3 carcinogen (limited evidence of a carcinogenic effect) and chronic toxicity (T; R48/23).

\subsection{Review of the Health Risks Associated with Nickel and Nickel Salts}

The literature provides evidence of nickel salts being carcinogenic [1-11] although not all publications support the findings. An assessment carried out by Oller in 2002 [12] found no proof that soluble nickel compounds caused cancer. What he did find was that high concentrations of soluble nickel salts could cause chronic respiratory toxicity and enhance the tumour response elicited by inhalation of carcinogens (such as cigarette smoke or insoluble nickel salts). A concern with epidemiologic studies of cancer is determining whether soluble nickel compounds have a causal or enhancing effect due to the lack of full data available. When conducting studies into nickel compounds and their carcinogenic effect, the factors that should be taken into account are: (1) Exposure limits; (2) Isolation of the person to just soluble or insoluble nickel compounds; (3) No contact with other known or suspected carcinogenic substances; (4) The health of the individual including family history of any cancers. Carcinogenic studies are difficult to conduct due to external factors that cannot be controlled. An example is the exposure to other known carcinogens such as cigarette smoke. A large proportion of the population smoke (1 in 4 people [13]) and the known carcinogenic effect of smoking and passive smoking are well known [14], so isolating the carcinogenic effect caused by nickel exposure alone becomes problematic.
Health risk associated with nickel dermatitis also known in the electroplating industry as "nickel itch" occurs when nickel salts are absorbed into the body. An allergic reaction takes place and in most cases, it can be seen in the form of a rash. Nickel allergy is one of the major factors for hand eczema; $30 \%-40 \%$ of people who are nickel sensitive suffer from it [15]. Different studies have found that an increase in contact time between nickel and the sweat solution increases the amount of nickel dissolved $[15,16]$.

\subsection{Legislative and Regulating Guidance on the Use of Nickel Compounds}

Controlling the risk of skin exposure to nickel and its salts within a work place can help prevent sensitisation. Less exposure to nickel reduces the risk of becoming sensitised. This can easily be done by following the COSHH (Control of Substances Hazardous to Health) regulations effective from 2002. It requires that skin exposure to nickel and its salts are prevented or adequately controlled at work. If prevention is not possible then the use of Personal Protective Equipment (PPE) is required; this would include gloves, eye protection and wearing overalls. The Health and Safety Executive (HSE) states that the role of PPE should only be used as a last resort for removing any risk to health; all other measures must be carried out first.

The public is exposed to nickel metal through everyday life. Costume jewellery uses nickel as a silver replacement to reduce costs and the clothing industry used nickel on belt buckles and buttons [17]. A person who is not sensitised to nickel would not react to these objects, but continuous contact with nickel could cause them to become sensitised. Stainless steel cutlery found in most households is not harmful to the majority of people who are sensitised to nickel because the nickel in the stainless steel is tightly bound in the alloy [17] and therefore not freely available on the surface. However there are people who are sensitised when handling stainless steel and are known to be "hyper-sensitive" to nickel [18]. In the UK, it is 
thought that $30 \%$ of the population is allergic to nickel with a higher percentage of women compared to men. It is not understood if the age or sex of a person is a determinant or other factors such as culture, occupation and habits. A plausible theory for the high percentage of women being allergic to nickel is because they are more likely to come into contact through piercings and jewellery while men tend to have contact through their work [19].

The need to seek an alternative replacement for nickel in spite of its utility in the plating industry is driven by the health and safety issues concerning its use. Soluble nickel compounds account for $12 \%-14 \%$ of the total nickel demand [20], therefore their reclassifications mean they must undergo the authorisation procedure of REACH (Registration, Evaluation \& Authorisation of Chemicals), a new law enforced from June 2007 to improve protection of human health and the environment. The chemical industry will now have greater responsibility to manage the volume of chemicals they handle and the risks the chemicals pose. Hazard information will be stored on a database and can be referred to by all concerned. REACH aims to progressively replace the more hazardous chemicals with less harmful alternatives as they are identified [21].

There are a few replacements proposed for nickel but only for a limited number of applications. A typical replacement is a copper-tin alloy called white bronze also known as speculum which has a similar appearance to silver [22]. The $\mathrm{Cu}-\mathrm{Sn}$ alloy is often plated over a bright copper deposit to give a luscious finish due to the $\mathrm{Cu}-\mathrm{Sn}$ alloy not having its own brightener system. Literature has shown the $\mathrm{Cu}-\mathrm{Sn}$ alloy to have better corrosion resistance than nickel, and offers good wear resistance which is an advantage for the jewellery industry [23]. There appears to be no commercial alternative for the replacement of nickel when used under chromium. If the nickel can be replaced this would reduce nickel exposure to both workers in the electroplating industry and the public as a whole.

\section{Experimental Procedures}

\subsection{Electroplating Sequence}

Brass panels (size $10 \times 7.5 \times 0.05 \mathrm{~cm}$ ) were prepared using a standard pre-treatment process which involved a cathodic electro-cleaner (Metex PS Activax) used at $80{ }^{\circ} \mathrm{C}$ at a current density of $0.3 \mathrm{amps} / \mathrm{dm}^{2}$ for $3 \mathrm{~min}$; this removed any oil and grease from the brass surface, then followed by an anodic cleaner (Metex PE E5) at $80{ }^{\circ} \mathrm{C}, 2 \mathrm{amp} / \mathrm{dm}^{2}$ for $3 \mathrm{~min}$, and then to finish the pre-treatment stage, the panels were soaked in an acid dip (Metex M-629) for $3 \mathrm{~min}$ to remove any oxide layers before plating. Fig. 1 shows the typical plating sequence for the standard nickel and chromium process. The panels were plated in the nickel electrolyte (NiMac Clarion II) at $55{ }^{\circ} \mathrm{C}$ at a current density of $4 \mathrm{amps} / \mathrm{dm}^{2}$ for $30 \mathrm{~min}$ to give a deposit thickness of $20 \mu \mathrm{m}$. The chromium electrolyte (TriMac III) if required is then plated at $60{ }^{\circ} \mathrm{C}$ and at a current density of $10 \mathrm{amps} / \mathrm{dm}^{2}$ for $12 \mathrm{~min}$ to give a deposit thickness of $0.3 \mu \mathrm{m}$.

Fig. 2 shows the plating sequence for the electrodeposition of the $\mathrm{Cu}-\mathrm{Sn}$ and chromium deposits. The brass panels were plated with bright copper (CuMac Rival) at $25{ }^{\circ} \mathrm{C}$ at a current density of 3 amps $/ \mathrm{dm}^{2}$ for $30 \mathrm{~min}$ to give a plating thickness of 20 $\mu \mathrm{m}$, then followed by the $\mathrm{Cu}-\mathrm{Sn}$ electrolyte (Starvet) used at $55^{\circ} \mathrm{C}$ at a current density of $1.0 \mathrm{amps} / \mathrm{dm}^{2}$ for 5 minutes for a plating thickness of $1 \mu \mathrm{m}$. If required the chromium electrolyte (TriMac III) was plated at $60{ }^{\circ} \mathrm{C}$ at a current density of $10 \mathrm{amps} / \mathrm{dm}^{2}$ for $12 \mathrm{~min}$ to give a deposit thickness of $0.3 \mu \mathrm{m}$. All pre-treatment solutions and electrolytes are available commercially and were supplied by MacDermid PLC.

The acid copper was plated to give the same overall deposit thickness as the standard nickel and chromium process. The $\mathrm{Cu}-\mathrm{Sn}$ deposit is not plated commercially above a few microns due to its change in appearance from a silvery bright deposit to a dull grey deposit (which is unsuitable as a nickel replacement). This 


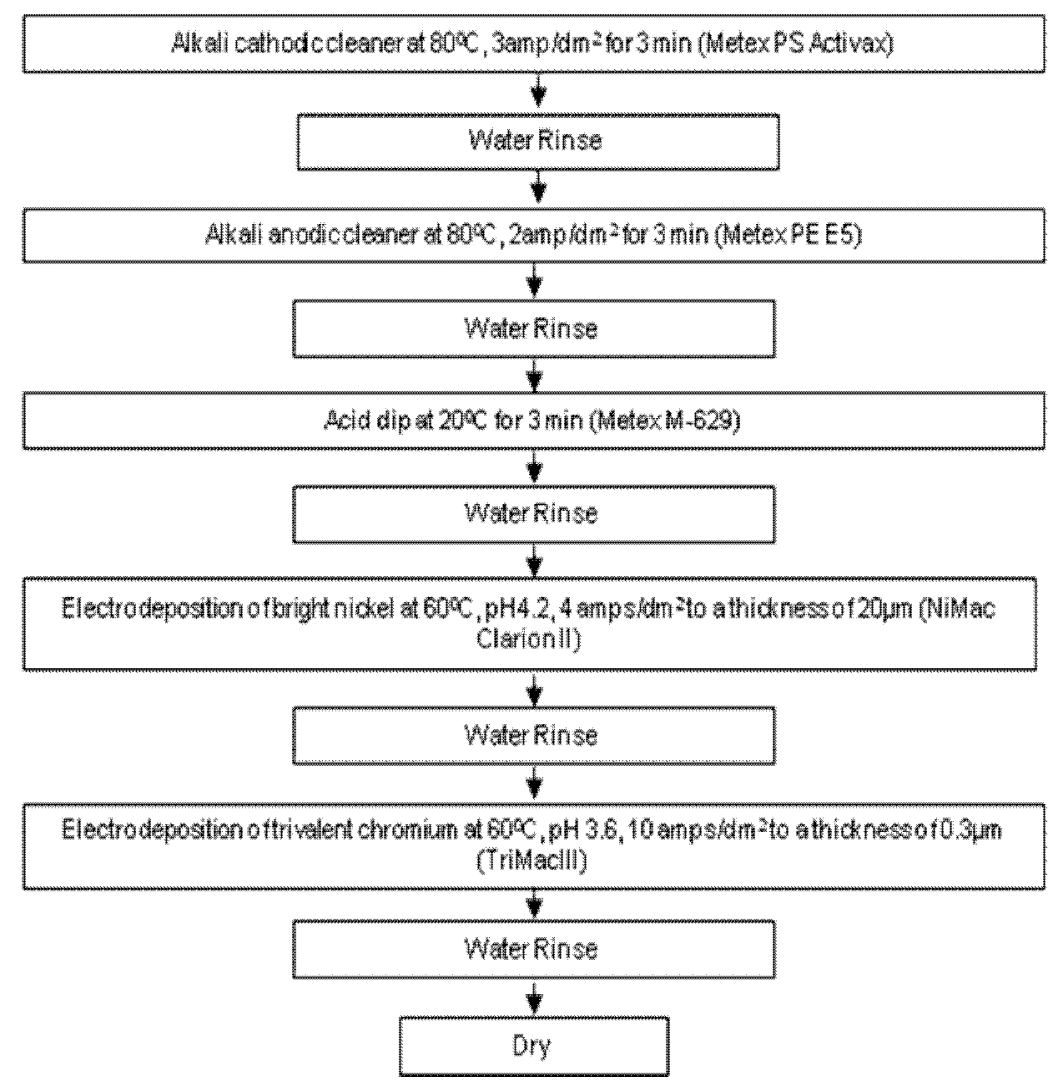

Fig. 1 Process sequence for the electrodeposition of bright nickel and trivalent chromium onto a brass substrate.

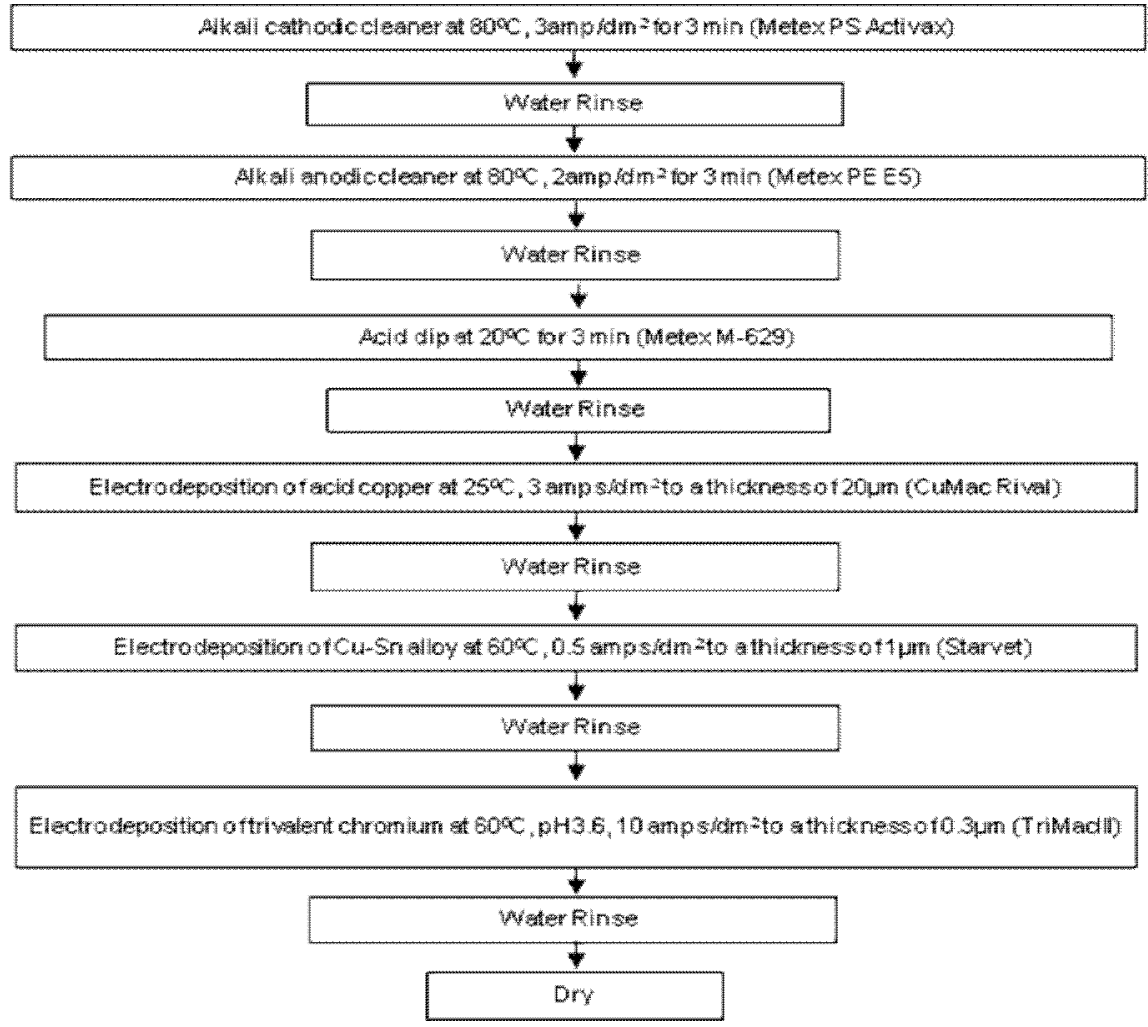

Fig. 2 Process sequence for the electrodeposition of $\mathrm{Cu}-\mathrm{Sn}$ deposit and trivalent chromium onto a brass substrate. 
approach allowed the corrosion testing to be comparable between the two plating sequences as they were of similar overall deposit thickness.

\subsection{Colorimetric Analysis}

Colorimetric analysis was carried out to determine the colour difference between the deposits. A spectrophotometer (Konica Minolta, model CM-2600d) was used to characterise the colour as a numeric value, therefore allowing a better comparison of colour without it being subjective [24]. The colour is reported using the $\mathrm{L}^{*} \mathrm{a} \mathrm{b}^{*}$ colour space, which allows an independent evaluation and consistency of results [25]. The readings were taken across the panel to account for high and low current density areas and the average reading taken.

$\mathrm{L}^{*}$ indicates lightness of the deposit, the values range from $0-100$, the higher the value the lighter the deposit.

$a^{*}$ indicates the red and green colour of the deposit, the values range being between -60 to +60 , the more positive the value the more red in colour, while the more negative the value the more green in colour.

$b^{*}$ indicates the yellow and blue colour of the deposit, the values range between -60 to +60 , the positive value stands for yellow while the negative value stands for blue.

\subsection{Atomic Force Spectroscopy (AFM) Analysis}

Atomic force spectroscopy (Veeco Dimension 3100) was used to calculate the roughness of the deposits by using the contact mode technique. This would help identify a more detailed surface characterisation of each deposit as it is able to quantitatively measure the surface roughness to a nanometer scale. Rmax (Eq. (1)) represents the maximum vertical distance between the highest and lowest data points in the same image following the plane fit. RMS (Eq. (2)) is the root mean square average of height deviations taken from the mean image data plane, the roughness calculation (RMS) is simple and most common method for observing any changes in the surfaces topography [26].

$$
\begin{aligned}
& R_{\max }= \frac{\sum\left|X-X_{0}\right|}{N^{0}} \\
& R M S=\frac{\sum\left(X-X_{0}\right)^{2}}{N^{-1}}
\end{aligned}
$$

where $X$ is the value of heights across the entire image and $N$ is the number of data points. A limitation with using RMS algorithm is that it will work with the best fit of all the height points and not the spatial frequency of the features.

\subsection{Corrosion Analysis}

Two different methods were used to inspect the corrosion performance of the different deposits. The first method was by linear polarisation, an electrochemical method where current is applied 20 $\mathrm{mV}$ either side of the open circuit potential. From this the corrosion current $\left(I_{\text {corr }}\right)$ and corrosion rate in millimetres per year (MPY) can be calculated. The second method is by visual corrosion observed on each sample; this is achieved by putting the samples in a corrosion cabinet and introducing a corrosive atmosphere to accelerate corrosion. This study used two types of corrosive atmospheres, 1) Neutral Salt Spray (NSS) and 2) Copper Accelerated acetic acid Salt Spray (CASS). Each method will be explained in more detail later in this section. Accelerated corrosion methods cannot be related to actual time and is subjective to the individual interpretation, but results are comparative to each other when tested to the same specification and evaluation.

\subsubsection{Linear Polarisation Measurements}

The corrosion current density $I_{\text {corr }}$ was determined by a linear polarisation method using a potentiostat $(E G+$ $\mathrm{G}$ Instruments, model 263A). This was carried out in $5 \%$ neutral sodium chloride solution using a $\mathrm{Ag} / \mathrm{AgCl}$ reference electrode over a potential range of $+/-20 \mathrm{mV}$ versus open circuit potential. The $1 \mathrm{~cm}^{2}$ surface area of the sample was left to equilibrate for $1 \mathrm{~h}$ in the $\mathrm{NaCl}$ solution. Each panel was analysed five times and the average value was reported. The corrosion current density can be converted to corrosion rate in 
millimetres per year (mpy) according to Eq. (3) [27].

$$
\mathrm{MPY}=I_{\text {corr }}(\Lambda)(1 / \rho)(\varepsilon)
$$

where $I_{\text {corr }}$ is the corrosion current density in amps $/ \mathrm{cm}^{2}$, $\Lambda$ is a combination of several conversion terms and is $1.2866 \times 10^{5}$ [equivalents.sec.ml]/[Coulombs.cm.year], $\rho$ is the metal density in grams $/ \mathrm{cm}^{3}, \varepsilon$ is the equivalent weight of the metal in grams (equivalent weight is the molecular weight of the metal divided by the number of electrons in the anodic half reaction).

Electrochemical corrosion measurements are used to accelerate the corrosion of the metal by applying a voltage which will push the metal/electrolyte interface beyond its steady state conditions, this causing an electrical current to flow which is measurable. The results can then be interpreted to determine the metallic corrosion behaviour and estimate the corrosion resistance [27].

\subsubsection{Neutral Salt Spray (NSS) Corrosion Analysis}

A 5\% sodium chloride solution was made to ASTM B117 specification $(50 \mathrm{~g} / \mathrm{L}$ sodium chloride, $\mathrm{pH}$ adjustment with sodium hydroxide or hydrochloric acid) and operated to the ASTM B117 specification. ASTM B117 specification is a popular standard used by industries such as the aerospace, automotive, military and medical to name a few [28]. The running of the test and evaluation will be standardised by each industry as they set out their own criteria for a pass depending on the level of corrosion protection required. This method is the least aggressive atmosphere out of the two conditions selected.

2.4.3 Copper Accelerated Acetic Acid Salt Spray (CASS) Corrosion Analysis

A salt solution was made to ASTM B368 specification $(50 \mathrm{~g} / \mathrm{L}$ sodium chloride, $0.25 \mathrm{~g} / \mathrm{L}$ copper chloride, $\mathrm{pH}$ adjustment with acetic acid). The corrosion cabinet was operated to the ASTM B368 specification. ASTM B368 was originally developed for chromium electroplating on nickel and chromium/nickel/copper electroplating [29]. It is a more aggressive test than ASTM B117 due to the more acidic environment and the addition of copper to the salt solution.

The corrosion rating for both NSS and CASS is measured according to ASTM B537 specification (standard practice for rating of electroplated panels subjected to atmosphere exposure). The first rating is assigned to the appearance as affected by corrosion of the substrate. A second rating is assigned to the appearance as affected by deterioration of the coating itself.

\section{Results}

\subsection{Colorimetric Results}

Comparing the colour difference of the deposits, the $\mathrm{Cu}-\mathrm{Sn}$ deposit was lighter and bluer than the bright nickel. The chromium deposit was lighter, greener and bluer than the bright nickel and the $\mathrm{Cu}-\mathrm{Sn}$ deposits. The colour of the chromium deposit remained constant showing the electroplated deposit underneath had little or no effect on the overall colour.

Table 1 shows the $\mathrm{L}^{*} \mathrm{a} * \mathrm{~b} *$ values obtained for each panel. For this study, $\mathrm{Cu}-\mathrm{Sn}$ deposit could not be plated to the same thickness as the bright nickel deposit, since above a few microns, the appearance of the deposit is sacrificed (giving a dull grey/silver deposit). The appearance of this thicker $\mathrm{Cu}-\mathrm{Sn}$ deposit therefore would not be an acceptable replacement for nickel.

\subsection{AFM Results}

The AFM results from this study identify the nickel deposit to be the smoothest of all the deposits characterised with an RMS and Rmax values of $3.08 \mathrm{~nm}$

Table 1 Average $L^{*} a * b *$ colour values for electroplated deposits.

\begin{tabular}{llrr}
\hline Deposit & L* & $\mathrm{a}^{*}$ & \\
\hline Bright nickel & 83.12 & 0.81 & 6.68 \\
Bright nickel + Chromium & 82.78 & -0.21 & 0.66 \\
Cu-Sn $(1 \mu \mathrm{m})$ & 86.26 & 0.40 & 3.25 \\
$\mathrm{Cu}-\mathrm{Sn}(1 \mu \mathrm{m})+$ Chromium & 82.89 & -0.26 & 0.93 \\
\hline
\end{tabular}


and $18.6 \mathrm{~nm}$ respectively. The $\mathrm{Cu}-\mathrm{Sn}$ deposit is the roughest of all deposits studied with the following RMS and Rmax values of $8.30 \mathrm{~nm}$ and $73.0 \mathrm{~nm}$, respectively. The chromium deposit increases the roughness of the nickel deposit giving RMS and Rmax values of $3.91 \mathrm{~nm}$ and $36.6 \mathrm{~nm}$, respectively, but reduces the roughness when plated onto the $\mathrm{Cu}-\mathrm{Sn}$ deposit with values of RMS $5.60 \mathrm{~nm}$ and Rmax 33.7 $\mathrm{nm}$. The acid copper deposit was found to have a RMS value of $5.92 \mathrm{~nm}$ and Rmax of $58.5 \mathrm{~nm}$. A thicker $\mathrm{Cu}-\mathrm{Sn}$ deposit was plated to show that the roughness increased with thickness to give a RMS value of 12.6 $\mathrm{nm}$ and Rmax value of $120.0 \mathrm{~nm}$. All results can be found in Table 2 and Figs. 3-8 show the AFM three dimension images of all the deposits plated.

\subsection{Corrosion Results}

\subsubsection{Linear Polarisation Results}

Linear polarisation results indicated that whilst $\mathrm{Cu}-\mathrm{Sn}$ deposit has similar corrosion current density to chromium plated deposit, the bright nickel deposit has a much higher corrosion current density compared to all other deposits. Table 3 shows the corrosion current densities for all panels plated. The corrosion rates show that the chromium deposit with either nickel or $\mathrm{Cu}-\mathrm{Sn}$ deposit underneath has the slowest corrosion rate of 0.024 and 0.034 , respectively. The nickel deposit has the highest corrosion rate of 0.285 mpy compared to all other deposits. From these results it would be expected that the $\mathrm{Cu}-\mathrm{Sn}$ deposit would show better corrosion resistance in the corrosion cabinets compared to the nickel deposit (this is not the case when evaluating the NSS and CASS) and the chromium deposit would provide the best protection overall (this was supported by the NSS and CASS results). It is important to note that the $I_{\text {corr }}$ value is an average corrosion current density of the surface and will not isolate areas of higher and lower corrosion current densities. The following assumptions were made when calculating the corrosion rate:

(1) The alloy composition of the $\mathrm{Cu}-\mathrm{Sn}$ deposit was 2 copper atoms to 1 tin atom with an average molecular mass;

(2) All deposits were assumed pure for the density value;

(3) All deposits were free from any defects on the surface.

\subsubsection{NNS Results}

The NSS corrosion cabinet results shown in Table 4 indicate that the bright nickel deposit had no corrosion defects after $24 \mathrm{~h}$ but did discolour, after $48 \mathrm{~h}$ the deposits appearance deteriorated but still provided protection to the substrate, while after $72 \mathrm{~h}$ the bright nickel deposit showed localised corrosion sites in a few areas down to the substrate. The bright nickel/chromium panels showed there were no defects or discolouration to the chromium deposit after $72 \mathrm{~h}$. Inspection of $\mathrm{Cu}-\mathrm{Sn}$ deposit after $24 \mathrm{~h}$ showed the appearance of corrosion sites. As testing continued, the $\mathrm{Cu}-\mathrm{Sn}$ deposits showed an increasing number of defects to the overall panel and corrosion spots through to the substrate were evident. The $\mathrm{Cu}-\mathrm{Sn} / \mathrm{chromium}$ deposit showed a slight increase in corrosion protection when compared to the $\mathrm{Cu}-\mathrm{Sn}$ deposit alone. The $\mathrm{Cu}-\mathrm{Sn} /$ chromium deposit did have increased corrosion defects when compared to the nickel/chromium coatings.

3.3.3 CASS Results

The CASS corrosion cabinet results presented in

Table 2 AFM Roughness Measurements.

\begin{tabular}{lcc}
\hline Deposit & RMS $(\mathrm{nm})$ & Rmax $(\mathrm{nm})$ \\
\hline Bright nickel & 3.08 & 18.6 \\
Bright nickel + Chromium & 3.91 & 36.6 \\
Acid copper & 5.92 & 58.5 \\
$\mathrm{Cu}-\mathrm{Sn}(1 \mu \mathrm{m})$ & 8.30 & 73.0 \\
$\mathrm{Cu}-\mathrm{Sn}(1 \mu \mathrm{m})+$ Chromium & 5.60 & 33.7 \\
$\mathrm{Cu}-\mathrm{Sn}(12 \mu \mathrm{m})$ & 12.6 & 120.0 \\
\hline
\end{tabular}




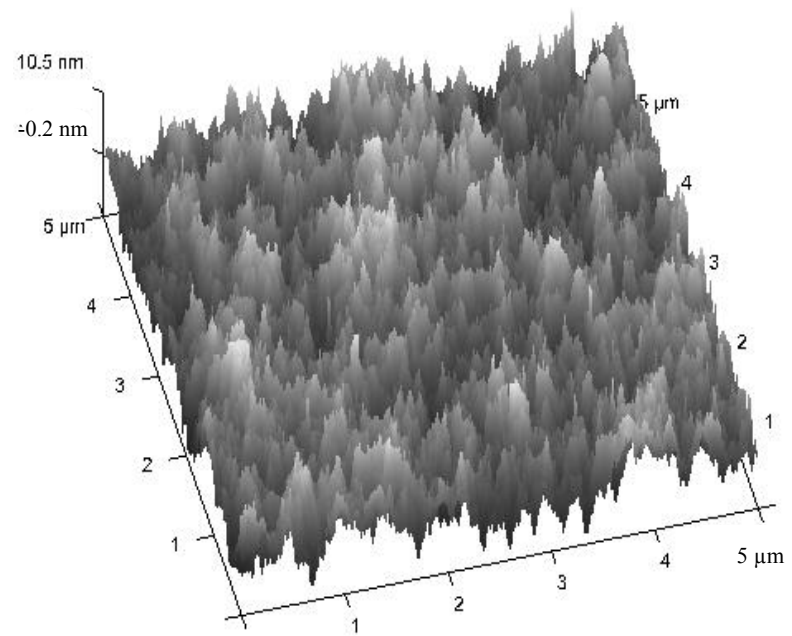

Fig. 3 AFM image of the nickel deposit.

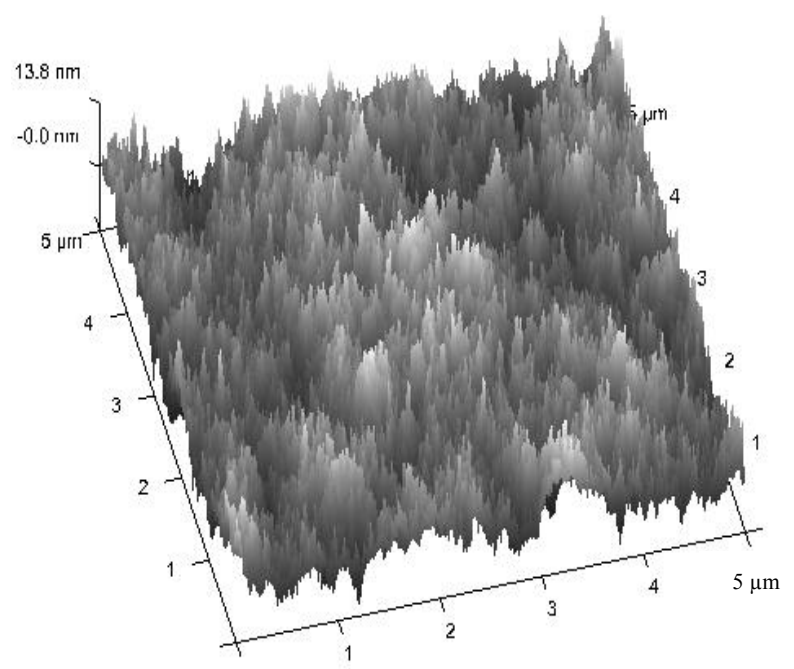

Fig. 4 AFM image of the nickel + chromium deposit.

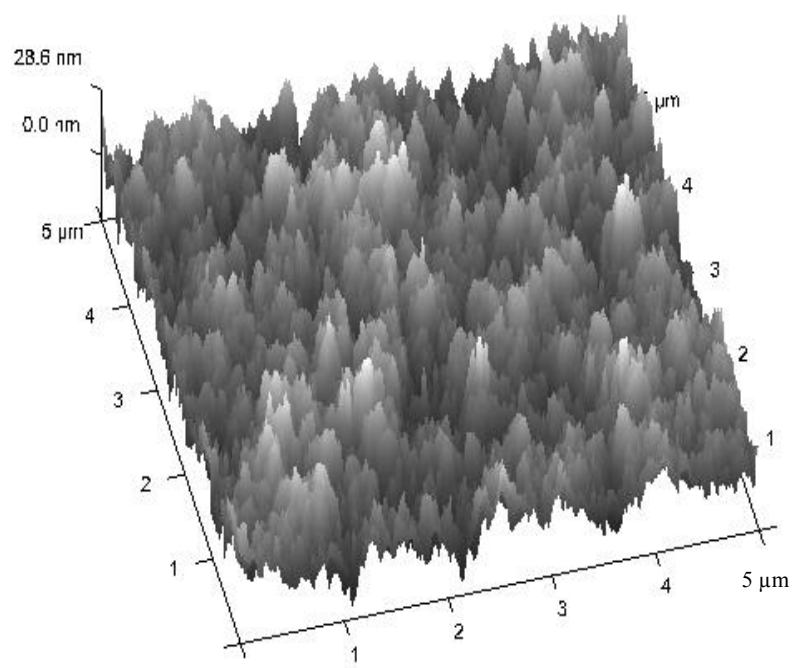

Fig. 5 AFM image of the Cu-Sn deposit $(1 \mu \mathrm{m})$.

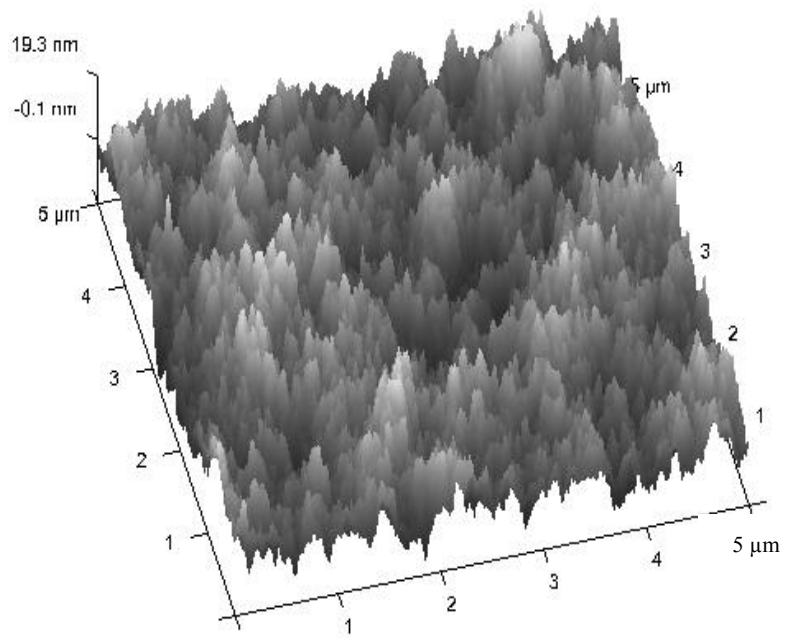

Fig. 6 AFM image of the Cu-Sn deposit + chromium deposit.

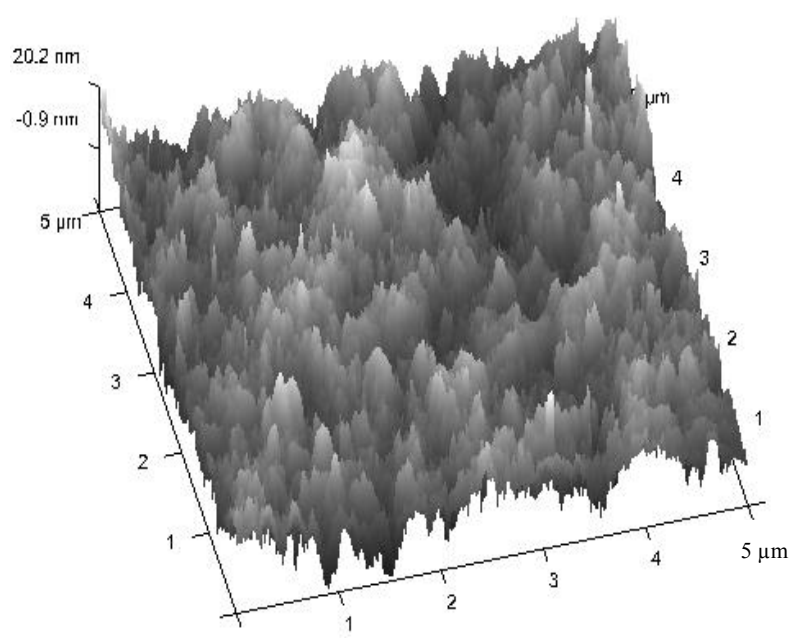

Fig. 7 AFM image of the acid copper deposit.

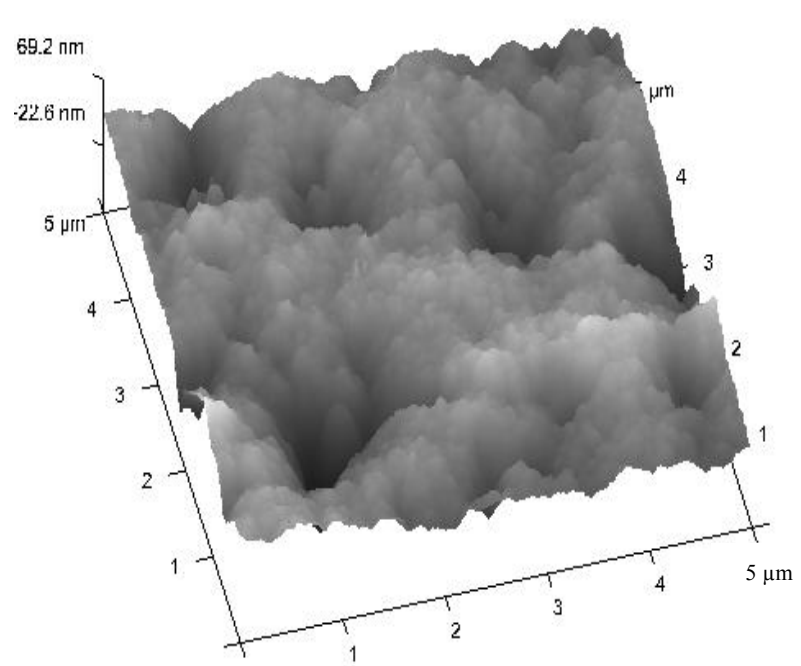

Fig. 8 AFM image of the Cu-Sn deposit (12 $\mu \mathrm{m})$. 
Table 3 Average $I_{\text {corr }}$ values for electroplated deposits.

\begin{tabular}{lcl}
\hline Deposit & Average $I_{\text {corr }}\left(\mathrm{nA} / \mathrm{cm}^{2}\right)$ & Corrosion rate $(\mathrm{mpy})$ \\
\hline Bright nickel & 483 & 0.285 \\
Bright nickel + chromium & 77 & 0.024 \\
$\mathrm{Cu}-\mathrm{Sn}(1 \mu \mathrm{m})$ & 197 & 0.232 \\
$\mathrm{Cu}-\mathrm{Sn}(1 \mu \mathrm{m})+$ chromium & 108 & 0.034 \\
\hline
\end{tabular}

Table 4 NSS results (ASTM B117).

\begin{tabular}{llll}
\hline Deposit & Rating after $24 \mathrm{~h}$ & Rating after $48 \mathrm{~h}$ & Rating after $72 \mathrm{~h}$ \\
\hline Bright nickel & $10 / 2$ & $8 / 2$ & $3 / 1$ \\
Bright nickel + chromium & $10 / 10$ & $10 / 10$ & $10 / 10$ \\
$\mathrm{Cu}-\mathrm{Sn}(1 \mu \mathrm{m})$ & $4 / 4$ & $4 / 4$ & $3 / 2$ \\
$\mathrm{Cu}-\mathrm{Sn}(1 \mu \mathrm{m})+$ chromium & $8 / 8$ & $6 / 5$ & $4 / 2$ \\
\hline
\end{tabular}

Table 5 CASS results (ASTM B368).

\begin{tabular}{lll}
\hline Deposit & Rating after $8 \mathrm{~h}$ & Rating after $16 \mathrm{~h}$ \\
\hline Bright nickel & $2 / 2$ & $1 / 1$ \\
Bright nickel + chromium & $10 / 10$ & $10 / 8$ \\
$\mathrm{Cu}-\mathrm{Sn}(1 \mu \mathrm{m})$ & $4 / 4$ & $4 / 4$ \\
$\mathrm{Cu}-\mathrm{Sn}(1 \mu \mathrm{m})+$ chromium & $6 / 6$ & $5 / 5$ \\
\hline
\end{tabular}

Table 5 established that the bright nickel deposit provided the least corrosion protection compared to all other deposits, while chromium plated onto bright nickel deposit provided the best corrosion protection. The nickel/chromium deposit after $8 \mathrm{~h}$ showed no visible corrosion sites, after $16 \mathrm{~h}$ small corrosion sites in the chromium deposit were starting to form. The inspection of the $\mathrm{Cu}-\mathrm{Sn}$ deposits after $8 \mathrm{~h}$ showed the corrosion had spread evenly over the panel, while after $16 \mathrm{~h}$ the $\mathrm{Cu}-\mathrm{Sn}$ deposit had not corroded as fast as the nickel deposit. The chromium plated onto the $\mathrm{Cu}-\mathrm{Sn}$ deposits did improve the corrosion protection compared to only the $\mathrm{Cu}-\mathrm{Sn}$ deposit alone, although corrosion sites were still visible. Overall, the chromium deposit provided better corrosion protection when plated on top of bright nickel compared to being plated onto $\mathrm{Cu}-\mathrm{Sn}$ deposit. When evaluating accelerated corrosion results such as in NSS and CASS, it is not possible to relate the results to actual corrosion performance. It can only be used as a comparison to other deposits that have undergone the same test.

\section{Discussion}

The $\mathrm{Cu}-\mathrm{Sn}$ deposit plated to a thickness of $1 \mu \mathrm{m}$ to obtain a bright silver finish is achieved by the bright copper substrate; the brightness of the copper penetrates through the thin $\mathrm{Cu}$-Sn deposit giving it the required bright finish, similar to that of nickel. The chromium plated over either nickel or the $\mathrm{Cu}-\mathrm{Sn}$ deposit shows little variation in colour, this proving the $\mathrm{Cu}-\mathrm{Sn}$ deposit could replace nickel in terms of appearance. The thicker $\mathrm{Cu}-\mathrm{Sn}$ deposit showed increased roughness when plated to $12 \mu \mathrm{m}$, thus scattering the light more and therefore the deposit appears dull and not comparable to the appearance of the nickel deposit. This concludes that there is a limit to the thickness the $\mathrm{Cu}-\mathrm{Sn}$ can be plated. The thinner $\mathrm{Cu}-\mathrm{Sn}$ deposit however has the disadvantage of it being porous; as a consequence the corrosion protection is reduced. The contradicting results of the linear polarisation and corrosion cabinet tests highlight the pores in the $\mathrm{Cu}-\mathrm{Sn}$ deposit. The electrochemical test indicate that the $\mathrm{Cu}-\mathrm{Sn}$ deposit provides more corrosion protection than the nickel deposit so therefore should be confirmed by the accelerated corrosion testing, however, as highlighted previously the results actually contradict each other. This can be explained by the $\mathrm{Cu}$-Sn deposit being porous, the pores 
in the deposit allow a corrosion path to the substrate and therefore not providing much in terms of corrosion protection (this was seen by the localised corrosion sites on the panels). The linear polarisation does not take into account of any surface defects or impurities of a deposit and therefore didn't highlight the pores.

Bright nickel deposits plated to a thickness of $20 \mu \mathrm{m}$ are not porous, this is shown by accelerated salt spray tests indicating localised corrosion sites. These sites tend to start where the deposit has a defect and therefore not spread evenly over the deposits surface. Pores however are spread evenly throughout the deposit and therefore a distinction between the two can be made. The difference seen between the nickel deposit and the $\mathrm{Cu}-\mathrm{Sn}$ deposit was that the nickel deposit showed only a few localised corrosion sites which increased in size with continued exposure to the salt solution, where the $\mathrm{Cu}-\mathrm{Sn}$ deposit had numerous but smaller corrosion sites all over the panel surface.

The chromium deposit is also porous similar to $\mathrm{Cu}-\mathrm{Sn}$ as it is only plated to $0.3 \mu \mathrm{m}$. As the pores are distributed evenly over the chromium surface, it is less likely that there would be localised corrosion sites as seen with the nickel deposit. The smaller areas of corrosion, which will start at a pore, are distributed evenly over the chromium surface and therefore provide a more aesthetically appealing deposit as it starts to corrode. The porous chromium deposit works well with a non-porous nickel deposit underneath as the corrosion can spread under the chromium deposit but not penetrate through the nickel to the substrate so fast, as shown by the corrosion ratings given to the nickel/chromium deposit compared to the $\mathrm{Cu}-\mathrm{Sn} /$ chromium deposit. The porous $\mathrm{Cu}-\mathrm{Sn}$ deposit provides a path for the corrosion to penetrate to the underlying coating in this case it is the acid copper. The idea was that the copper would provide the same non-porous layer as the bright nickel deposit, but although the copper deposit is non-porous it corrodes faster than the nickel so the corrosion starts becoming visible over the whole deposit, thus compromising the overall appearance of the deposit.

Once the deposits are exposed to $16 \mathrm{~h}$ CASS or $72 \mathrm{~h}$ NSS it is seen that there is little difference between the $\mathrm{Cu}-\mathrm{Sn}$ and bright nickel deposit, thus demonstrating that corrosion as soon as it has been established whether localised or evenly distributed over the surface, eventually the deposit reaches a level where corrosion becomes clearly visible. Overall, the best protection against corrosion is the widely used bright nickel/chromium deposit as it outperforms all the other deposits tested in this study.

\section{Conclusions}

The objective of this study was to characterise a $\mathrm{Cu}-\mathrm{Sn}$ deposit and determine if it was a practical alternative to the nickel layer under decorative chromium. On the basis of this study the following conclusion was reached. The $\mathrm{Cu}-\mathrm{Sn}$ deposit could replace the nickel layer under chromium to produce an acceptable appearance but it could not match the same corrosion performance as the nickel deposit under chromium; therefore the $\mathrm{Cu}-\mathrm{Sn}$ deposit would not be a suitable replacement for the nickel deposit where corrosion protection is primary. Other conclusions drawn from this study are as follows:

(1) The colour of the chromium deposit does not vary greatly when plated on to either $\mathrm{Cu}-\mathrm{Sn}$ deposit or bright nickel deposit;

(2) The $\mathrm{Cu}-\mathrm{Sn} /$ chromium deposits do not provide the same level of corrosion protection as nickel/chromium deposits;

(3) The corrosion rate of the $\mathrm{Cu}-\mathrm{Sn}$ deposit is lower than bright nickel indicating that it could provide better corrosion protection to the substrate if the deposit was not porous;

(4) $\mathrm{Cu}-\mathrm{Sn}$ deposit will not replace nickel where corrosion protection is required;

(5) $\mathrm{Cu}-\mathrm{Sn} /$ chromium deposits have the potential to replace nickel/chromium deposits where used primarily for cosmetic appearance and in a moderately corrosive atmosphere. 


\section{Acknowledgments}

The authors wish to show their gratitude to the EPSRC, Kohler-Mira PLC and MacDermid PLC for the sponsorship of this project and also MacDermid PLC for the use of their chemicals and equipment. S.L. Handy would like to thank the School of Engineering and Built Environment, University of Wolverhampton for their support during the course of this study.

\section{References}

[1] T.K. Grimsrud, S.R. Berge, J.I. Martinsen, A. Andersen, Lung cancer incidence among Norwegian nickel refinery workers 1953-2000, J. Environ. Monitor. 5 (2003) 190-197.

[2] IARC, Report of the International Committee on Nickel Carcinogenesis in Man, Work-Environment-Health, IARC, 1990.

[3] K.S. Kasprzak, F.W. Sunderman, S. Salnikow, Nickel carcinogenesis, Mutat. Res. 533 (2003) 67-97.

[4] M. Kiilunen, J. Utela, T. Rantanen, H. Norppa, A. Tossavainen, Exposure to soluble nickel in electrolytic nickel refining, Ann. Occup. Health 41(1997)167-188.

[5] R.E.G. Rendall, J.I. Phillips, K.A. Renton, Death following exposure to fine particulate nickel from a metal arc process, Ann. Occup. Health 38 (1994) 921-930.

[6] K. Salnikow, K.S. Kasprzak, Ascorbate depletion: a critical step in nickel carcinogenesis, Environ Health Persp. 113 (2005) 577-584.

[7] E. Symanski, W. Chan, C. Chang, Mixed effects model for the evaluation of long-term trends in exposure levels with an example from the nickel industry, Ann. Occup. Health 45 (2001) 71-81.

[8] P. Bright, P.S. Burge, S.P. O'Hickey, P.F. Gannon, A.S. Robertson, A. Boran, Occupational asthma due to chrome and nickel electroplating, Thorax 52 (1997) 28-32.

[9] R.E. Waller, The combined effects of smoking and occupational or urban factors in relation to lung cancer, Ann. Occup. Health 15 (1972) 67-71.

[10] WHO, IARC Monographs on the Evaluation of Carcinogenic Risk to Humans, 1990.

[11] M.A. Zoroddu, L. Schinocca, T. Kowalik-Jankowska, H. Kozlowski, K. Salnikow, M. Costa, Molecular mechanisms in nickel carcinogenesis: modeling $\mathrm{Ni}$ (II) binding site histone H4, Environ. Health Persp. 110 (2002) 719-723.

[12] A.R. Oller, Respiratory carcinogenicity assessment of soluble nickel compounds, Environ. Health Persp. 110 (2002) 841-844.
[13] National-Statistics Smoking, 2006, available online at: http://www.statistics.gov.uk/CCI/nugget.asp?ID=1327\&P os $=2 \&$ ColRank $=1 \&$ Rank $=326$.

[14] Cancer-Research, Smoking and Cancer, 2008, available online at: http://info.cancerresearchuk.org/healthyliving/ smokingandtobacco/.

[15] C. Linden, S. Carter, Nickel release from coins, Contact Dermatitis 44 (2001) 160.

[16] J.D. Hemingway, M.M. Molokhia, The dissolution of metallic nickel in artificial sweat, Contact Dermatitis 16 (1987) 99-105.

[17] A.K. Cerveny, R.T. Brodell, Blue jean button dermatitis nickel allergy presenting as a periumbilical rash, Postgrad Med. Minneapolis 112 (2002) 79.

[18] P. Haudrechy, J. Foussereau, B. Mantout, B. Baroux, Nickel release from 301 and 316 stainless steel in synthetic sweat, Comparision with nickel and nickel plated metals, Corros. Sci. 35 (1993) 329-336.

[19] C. Kwangsukstith, H.I. Maibach, Effect of age and sex on the induction and elicitation of allergic contact dermatitis, Contact Dermatitis 33 (1995) 289-298.

[20] Nickel-Institute, EU Risk Assessment Communication Workshop, 2005.

[21] REACH, What is REACH? 2009, available online at: http://ec.europa.eu/environment/chemicals/reach/reach_in tro.htm.

[22] F. Simon, Alternative for nickel in electroplating processes, Plat. Surf. Finish 81 (1994) 16-19.

[23] F. Simon, New tin alloy electrolytes for deposition of functional and decorative layers, AESF Surface Finishing Technology, Into the Millennium Electroplaters and Surface Finishing (2000) 359-367.

[24] Kioskea.net CIE/Lab (L*a*b) coding, 2008, available online at: http://en.kioskea.net/contents/video/cielab.php3.

[25] Konica-Minolta, Precise Color Communication, Konica Minolta Sensing Inc, 1998.

[26] A.M. Skolnik, W.C. Hughes, B.H. Augustine, A metallic surface corrosion study in aqueous $\mathrm{NaCl}$ solution using atomic force microscopy (AFM), Chemical Educator 5 (2000) 8-15.

[27] W.S. Tait, An Introduction to Electrochemical Corrosion Testing for Practicing Engineers and Scientists, Plan O Docs Publications, USA, 1994.

[28] IHS Standards, 2008, available online at: http://global.ihs.com/search_res.cfm?RID=Z56\&MID=52 80\&input_doc_number $=$ ASTM $\% 20 B \% 20117 \&$ s_kwcid= astm\%20b117|2885220074\&gclid=CKjXuqzQ-poCFZF_ 3 godJEGRew.

[29] ASTM, ASTM B368-09, 2009, available online at: http://www.astm.org/Standards/B368.htm. 